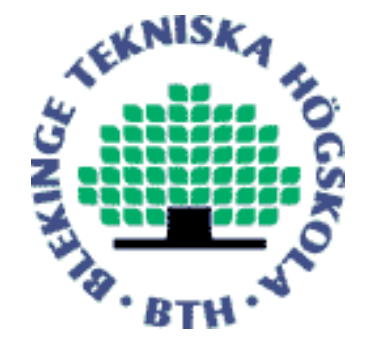

Copyright (C) 2014 IEEE.

Citation for the published paper:

A Cloud Model for Interoperable Home-based Chronic Diseases Healthcare

Yan $\mathrm{Hu}$, Guohua Bai

International Conference on Computer Medical Applications, ICCMA

2014 Sousse, Tunisia

This material is posted here with permission of the IEEE. Such permission of the IEEE does not in any way imply IEEE endorsement of any of BTH's products or services Internal or personal use of this material is permitted. However, permission to reprint/republish this material for advertising or promotional purposes or for creating new collective works for resale or redistribution must be obtained from the IEEE by sending a blank email message to pubs-permissions@iee.org.

By choosing to view this document, you agree to all provisions of the copyright laws protecting it. 


\section{A Cloud Model for Interoperable Home-based Chronic Diseases Healthcare}

\author{
Yan $\mathrm{Hu}$ \\ Department of Creative Technologies \\ Blekinge Institute of Technology \\ 37179,Karlskrona, Sweden \\ yhx@bth.se
}

\author{
Guohua Bai \\ Department of Creative Technologies \\ Blekinge Institute of Technology \\ 37179, Karlskrona, Sweden \\ gba@bth.se
}

\begin{abstract}
- traditional hospital based care cannot meet all the needs of chronic diseases care in home, especially for elderly people. A new approach applying eHealth that supports interoperable health care is required. To find a way to meet the new needs, we firstly carried out a questionnaire to analyze current problems and needs in chronic disease care. Then we compared possible technical solutions and proposed a cloud model for the identified problems. This model would help chronic patients self-record and control their daily care data, communicate with other patients who have the similar situation. The proposed solution could be also used to integrate data from different healthcare providers for a cooperative work, namely in this paper as Home-based Chronic Diseases Healthcare (HCDH).
\end{abstract}

Keywords-eHealth, home-based chronic disease healthcare, cloud, interoperability

\section{INTRODUCTION}

As a result of increased life expectancy and declining birth rate, the population of elderly is rising rapidly. Today there are around 810 million persons aged 60 or above in the world. The number will reach almost 2 billion by 2050 [1]. At the same time, chronic diseases have now become the leading causes of death [2]. It represents a huge global challenge for healthcare. Treating chronic diseases heavily depends on the patients daily behaviors. Living with a chronic disease has a significant impact not only on a person's quality of life but also their family and the current healthcare system. Elderly people living with more than one chronic disease face particular challenges, both medically and socially. The quality of their life could be greatly improved by a better care of chronic diseases [3].

With the increasing of home based healthcare services in Europe, the problem of not being able to respond due to lack of personnel and nursing for homes is well reported [4]. Meanwhile, ICT evolution has led to use of wireless personal devices like smartphones, personal computers and other selfmonitoring devices. This can provide with a solution to help home based healthcare. However, there is an interoperability problem with those technologies. To solve this interoperability problem, an eHealth approach based on cloud computing is proposed in this paper.

Sweden has published a new National Strategy for eHealth [5]. The focused problems have been shifted from the development of ICT in healthcare services to coordinated healthcare across the entire sectors to promote coherence and efficiency to all health and social care activities. There were three main requirements of eHealth areas in the National
Strategy [5]; they are: (1) Putting the individual needs in the first place, (2) National coordination for healthcare services. (3) Greater focus on e-issues nationally and internationally.

To provide safe and efficient interoperable home based healthcare needs high performance ICT technologies. Because of the high demand of workload for uploading and sharing huge amount of patient dairy health data, traditional serverclient computing system is no longer suitable. Cloud computing provides a better way to achieve the goal. According to the definition of U.S. National Institute of Standards and Technology [6], "cloud computing is a model for enabling ubiquitous, convenient, on-demand network access to a shared pool of configurable computing resources that can be rapidly provisioned and released with minimal management effort or service provider interaction." The main features of cloud services are flexibility, interoperability, economy and security, which make it possible to use service in everyone's daily life.

In this paper, we started with presenting challenges in chronic diseases healthcare, analyzed home-based care and healthcare information sharing demands based on our online questionnaires. Then we compared main eHealth interoperability techniques and found out cloud computing is the most suitable for HCDH. We proposed our cloud home care model, which is based on a PaaS (platform as services) and included some software services. The benefits of this model were discussed with user cases.

\section{CHALLENGES IN CHRONIC DISEASES HEALTHCARE}

Chronic diseases, such as cardiovascular disease, chronic obstructive pulmonary disease and diabetes, have become a main challenge to health sectors around the world. The incidence and prevalence of chronic diseases is continuing to increase [7]. Focusing on the features of chronic diseases care, traditional hospital based healthcare could not meet all the needs for chronic diseases care. There are some new challenges.

\section{A. Lack of patients centered healthcare system}

The traditional healthcare systems were designed for acute diseases [8]. That means most of the computer or mobile based healthcare systems were targeted for healthcare providers, either manage patients' healthcare records, control pharmaceutical, or help for diagnoses. Although there are several home based healthcare systems in service now, few of them integrated with other systems [9]. 


\section{B. Lack of cooperation among healthcare providers}

The traditional responsibilities among healthcare providers are independent. However chronic diseases care needs efforts from all the evolved stakeholders, not only healthcare providers, but also receivers themselves and their families. Chronic diseases care is normally home based. The care providers are diverse, so the communication and cooperation are even more significant [10]. On the other hand, because of the mobility of healthcare receivers, different nations and regions have different healthcare laws and guidelines. Sometimes it leads to a waste of time and resource due to poor collaboration. Overall the current chronic healthcare has gaps of waste, overlap, delay and lack of collaboration, of which mainly are interoperability problems.

\section{Lack of Standards or guidelines for chronic diseases care}

Although there are some international standards of healthcare like HL7 [12], or some national guidelines for primarily care [13], there is no standard specific for chronic diseases care. In some cases, the unclear responsibility of care badly reduces the quality of $\mathrm{HCDH}$ [10] [11].

\section{Lack of educations for healthcare}

Chronic diseases could be controlled by patients' daily behaviors. One important part of home care is education, which means care providers should teach care receivers and their families the knowledge of their diseases. It will help chronic diseases patients manage and control themselves more efficiently. There are some education programs carrying out in developed countries [10], but most are regional. In developing countries, popularizing rate of chronic diseases healthcare education is lower [14]. Governments and organizations could pay more attention to the pervasive chronic diseases education. It is a strategy for improving chronic diseases care quality.

To overcome these challenges, a possible innovation might be from ICT, a new eHealth approach. Today patients who suffer chronic diseases have to be checked and monitored from time to time, and result in high cost, time consuming and inconvenient for patients [7]. Meanwhile, most of the cases for chronic diseases do not need urgent medical diagnosis and treatment. It is therefore more appropriate to adopt an efficient approach to trace and control the patients' conditions via healthcare services such as physiological signals monitoring and recording [15] in the home environment.

\section{ONLINE QUESTIONNAIRE ANALYSIS}

We conducted an online questionnaire of people aged 60 or above through some social media websites. The aims of this questionnaire are to know their current healthcare conditions, their views on home based healthcare and healthcare information sharing. In the end, we received 35 acceptable responses. Respondents are mainly elderly people from US and EU countries. There are 10 questions in it, which are listed in the following table.
TABLE 1 QUESTIONS OF QUESTIONNAIRE

\begin{tabular}{|c|c|c|}
\hline No. & Question & Answers \\
\hline 1 & Do you have any chronic diseases? & $\square$ Yes $\square$ No \\
\hline 2 & $\begin{array}{l}\text { What is your main way of receiving } \\
\text { healthcare? }\end{array}$ & $\begin{array}{l}\square \text { I visit Hospital or other } \\
\text { healthcare center. } \\
\text { Healthcare providers visit me } \\
\text { in my home. } \square \text { Mixed, } \\
\text { sometimes communicate by } \\
\text { phone or internet. }\end{array}$ \\
\hline 3 & $\begin{array}{l}\text { Do you have any communication } \\
\text { troubles with your current } \\
\text { healthcare providers? }\end{array}$ & Open question \\
\hline 4 & $\begin{array}{l}\text { Do you have any home healthcare } \\
\text { monitoring or testing devices? }\end{array}$ & $\square$ Yes $\square$ No \\
\hline 5 & $\begin{array}{l}\text { Would you like to self-manage some } \\
\text { of your personal healthcare data? }\end{array}$ & $\begin{array}{l}\square \text { Yes } \square \text { No } \\
\square \text { I have no confidence to do it } \\
\text { myself. }\end{array}$ \\
\hline 6 & $\begin{array}{l}\text { Would you like to share some of } \\
\text { your daily health data to your } \\
\text { authorized healthcare providers? }\end{array}$ & $\begin{array}{l}\square \text { Yes } \square \text { No } \\
\square \text { It depends }\end{array}$ \\
\hline 7 & $\begin{array}{l}\text { Would you like to share some of } \\
\text { your daily health data to your } \\
\text { relatives? }\end{array}$ & $\begin{array}{l}\square \text { Yes } \square \text { No } \\
\square \text { It depends }\end{array}$ \\
\hline 8 & $\begin{array}{l}\text { Would you like to share some of } \\
\text { your daily health data to some } \\
\text { research institution anonymously? }\end{array}$ & $\begin{array}{l}\square \text { Yes } \square \text { No } \\
\square \text { It depends }\end{array}$ \\
\hline 9 & $\begin{array}{l}\text { Would you like to have an online } \\
\text { community with same symptom } \\
\text { chronic disease people? }\end{array}$ & $\begin{array}{l}\square \text { Yes } \square \text { No } \\
\square \text { It depends }\end{array}$ \\
\hline 10 & $\begin{array}{l}\text { If there is one healthcare IT platform } \\
\text { that integrate all the functions } \\
\text { mentioned above (shearing some } \\
\text { data securely, self-management, } \\
\text { care receivers community etc.), } \\
\text { would you like to try it? }\end{array}$ & $\square$ Yes $\square$ No \\
\hline
\end{tabular}

The results show some today's problems in receiving healthcare, as well as their wishes on sharing healthcare information with their healthcare providers and other chronic diseases patients with similar symptoms.

\section{A. Common health conditions for elderly over 60}

Among all the respondents, $85.71 \%$ elderly people have one or more chronic diseases. This high rate means most of them need continuous but not urgent healthcare. $31.43 \%$ people only visit hospitals or healthcare providers to receive healthcare. Besides visiting, $62.82 \%$ of people sometimes use the telephone or internet to commute with providers. When asking about communication troubles with healthcare providers, the answers are varied, but mainly responded with troubles as too long waiting time, inconvenient to visit hospitals and lack of cooperation between healthcare providers. 
What is your main way of receiving healthcare?

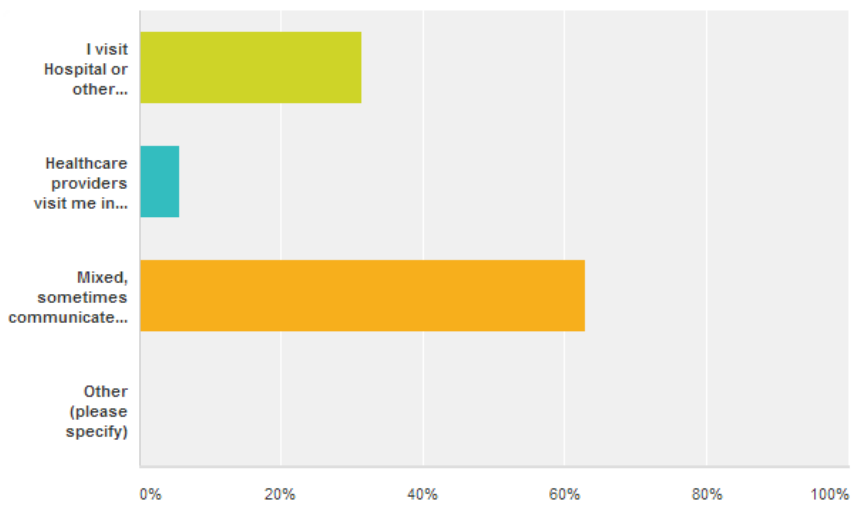

Figure 1 Answers of current healthcare conditions

\section{B. Views on home based healthcare}

In our questionnaire, more than half elderly people have home healthcare monitoring or testing devices. Also from the high rate of telephone and internet to communicate, these people have already accepted ICT tools for their daily healthcare, and it is possible for them to have home based healthcare. The questionnaire also shows that $80 \%$ of people would like to self-manage some of their personal healthcare data. $11.43 \%$ people have no confidence to do it themselves. If care educations are conducted well, they are also willing to do self-management with their own data.

Would you like to self-manage some of personal healthcare data?

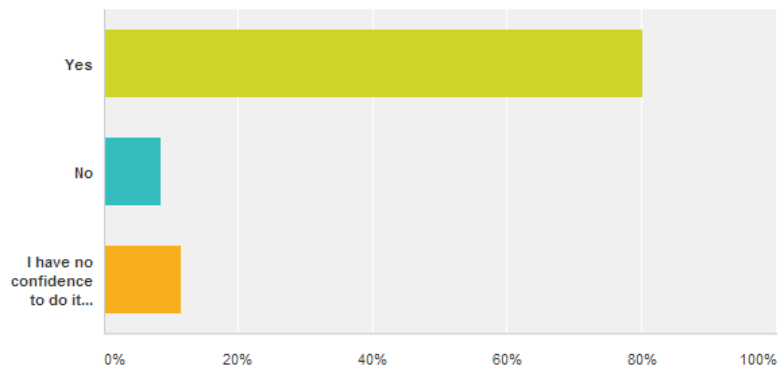

Figure 2 Answers of self-management

\section{Views on healthcare data sharing}

We asked four different kinds of possible sharing ways of their healthcare data. They are: (1) Share some daily health data to authorized healthcare providers. (2) Share some daily health data to relatives. (3) Share some daily health data to some research institution anonymously. (4) Have an online community other chronic diseases patients who have similar symptoms. All four kinds of sharing ways have more than half supports. One third chose "it depends" that means they are willing to sharing their healthcare data in some conditions or partly. To our surprise, communication with people who have same chronic diseases got the most support (88.57\%). It requires that the new approach should not only effort on interpretability between healthcare providers and receivers, or among healthcare providers, but also among healthcare receivers.

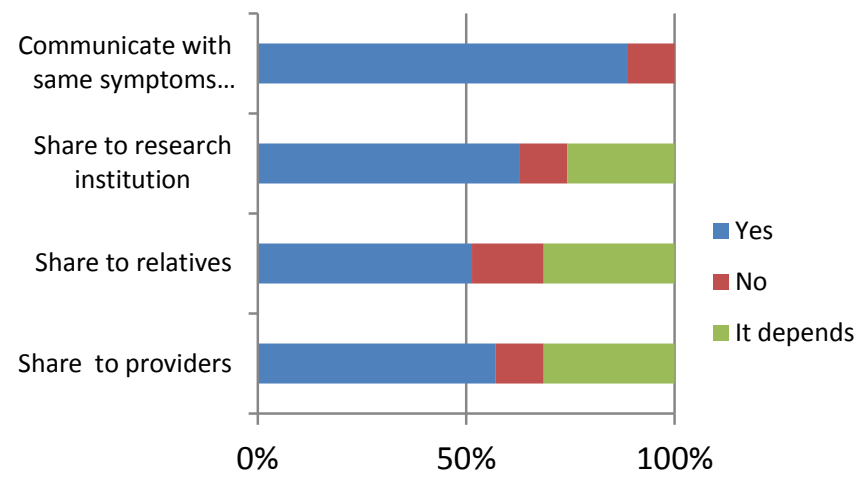

Figure 3 Answers of healthcare data sharing

The final question is if they are willing to have one healthcare IT platform that integrates all the functions mentioned. Nearly $90 \%$ participants would like to use it as their daily home based healthcare platform.

\section{ClOUd COMPUTING SERVICE FOR E-HEALTH}

The most significant challenge of home based healthcare for chronic diseases patients is interoperability. Interoperability among distributed and heterogeneous eHealth systems is complex because it involves data security and individual privacy. There are three main current techniques, cloud computing, peer-to-peer (P2P) network and Simple Object Access Protocol (SOAP) for achieving interoperability in eHealth.

We found that scalability is one of the benefits of using cloud computing, it can handle high traffic by easily adding more additional hardware infrastructure with no effect on the running service. This relies on large scale infrastructures and complex cloud systems while P2P and SOAP are lightweight and simpler to adapt in existing systems. Management is another primary benefit by using cloud computing compare with P2P and SOAP. The powerful management of cloud computing can provide different levels of access control for one piece of data. This guarantees the privacy of healthcare data. In the cloud, every piece of data can be managed by different security tools. P2P and SOAP both have been used for a long time, so there is no adopting cost. Furthermore, one feature of cloud computing, which can never be achieved through $\mathrm{P} 2 \mathrm{P}$ or SOAP, is various applications can be built on one cloud computing platform. All the data in the cloud storage can be obtained by these applications directly. This makes cloud a better technique for home based healthcare. Mass data storage also makes it possible for healthcare receivers' daily data management in the cloud.

In $\mathrm{HCDH}$, privacy, access control, data security and integration are main challenges. The unique advantages of cloud computing have the potential to overcome these challenges. Neither P2P nor SOAP could meet all the requirements of $\mathrm{HCDH}$. According to our previous research [16] [17], we used same scenarios for developing prototypes of sharing healthcare data with P2P based solution and cloud based solution. Comparing these two techniques, one obvious 
advantage of cloud is that healthcare receivers can easily enroll in the sharing platform. Another one is that once the providers or receivers access to the cloud, they can decide which data can be shared and to whom it can be shared. In addition, a number of self-control decision support systems can be embedded in the cloud based platform. It can help healthcare receivers have a better self management.

Cloud computing is a new computing approach which uses software, infrastructure and platform as service handover. Unlike traditional computing such as web hosting, cloud computing offers pay-as-you-go services. It gives users the possibility to pay for the resources they actually use for a time period [18]. Cloud offers many advantages, such as economy of scale, availability, management, efficiency, consolidation, cost and energy saving. This helps cloud users better utilize the computing resources, as well as minimize the costs. Although there are different ways of classification of cloud computing, the cloud service is classified based on the service model " $\mathrm{X}$ as services". These three layers are Infrastructure, Platform and Software, which are dependent on the type of services being offered [19] [20]. For HCDH, the main service model is platform as services, many applications of software as services are also widely used, such as:

1) Online software services: Cloud computing services can support almost any type of medical software applications for healthcare organizations. It also provides real-time software updates as well as online maintenance. Different healthcare providers and receivers can customize different healthcare software applications based on their needs. The infrastructure formed by a large number of systems connected can be shared. This service greatly reduces the software license fees of providers and receivers. They pay for services only when they are in need of services. It also enables the healthcare information technology standard to be improved. This service reduces the demand for hardware, only a laptop equipped with a browser or a smart phone, can be used for quick access to medical information efficiently.

2) Data storage services: Data storage services could help to build healthcare information integration platform to integrate different healthcare providers. Thus, necessary medical information resources will be shared between healthcare providers and receivers. For example, when patients update their daily care data in the cloud, this data will be collected and stored. Care providers or their relatives can easily browse the health data if necessary. This ensures home based care can be as efficient as hospital based care because all the home care data is already stored.

3) Computational Analysis Services: The computation capacity provided by cloud with mass data computing will improve the ability of large scale medical data analysis, as well as the depth of medical data mining. Find the association rules among mass data can give some comprehensive and accurate decision supports not only for healthcare providers, but also inspire healthcare receivers' confidence to manage their own daily healthcare data. The improvements of medical data collation and processing will also benefit the doctors to provide a lot of scientific evidence for high-efficiency and high-quality diagnosis.

\section{PROPOSED SOLUTION}

Based on analyses of the online questionnaire, we list main needs of the HCDH cloud platform.

- Self daily behavior controlling plays an important role in chronic disease healthcare, which means the new proposed solution should support healthcare receivers to do some self-managements of their own cares.

- Personal health records can be shared with people who have the access rights to the platform, as well as the data sources can decide the level of sharing.

- Based on the healthcare receivers' daily health information, the platform could automatically send reminders or alarms to the responsible healthcare stakeholders.

- Communities among healthcare receivers who have similar chronic diseases would be built so that they can help each other.

The proposed solution is based on a PaS model and includes some software services. Figure 4 shows a cloud based platform for chronic disease healthcare, which can support healthcare data exchange, storage and processing. This proposed model could build a bridge for current gaps of $\mathrm{HCDH}$, and help care receivers get more effective care as well as improve their life quality.

In this model, based on the data input to the cloud, computational analysis services can automatically process the data and send related requirements to the responsible care providers or care receivers themselves. All the input data can be stored and exchanged in the cloud. Authenticated users of the cloud, either care providers, or receivers at home could browse the remote healthcare records whenever they want. Some particular diseases' online software services are embedded in the cloud. Chronic healthcare receivers could choose these services according to their own conditions. They could also exchange care experiences and establish a bond with other chronic disease patients who have similar symptoms.

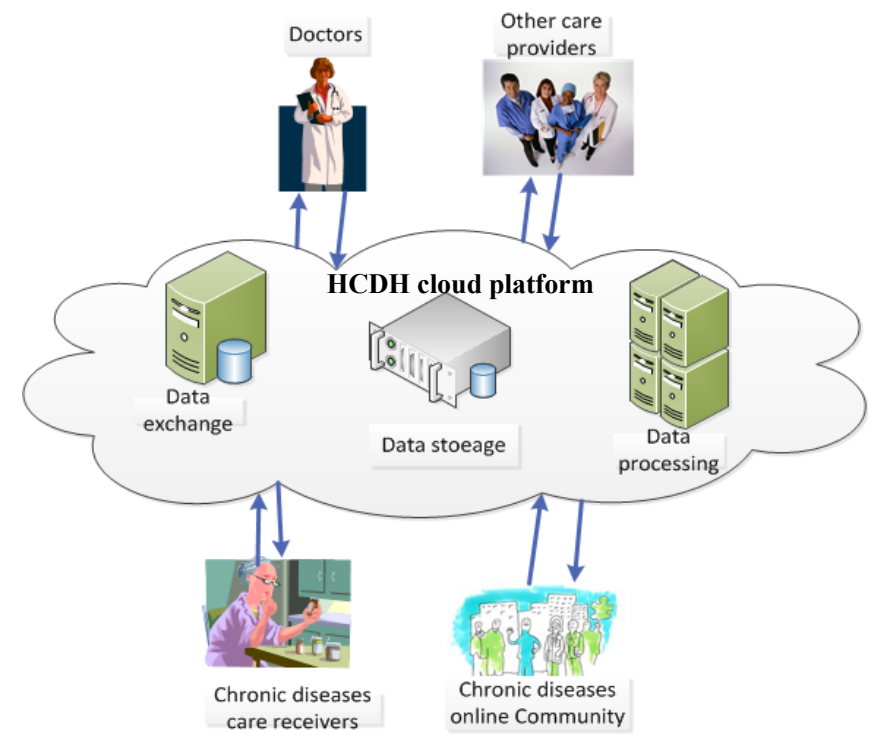

Figure 4 HCDH Cloud Platform 


\section{USER CASES}

To explain how the different components work together in the proposed model, we demonstrate three user cases to describe actions of healthcare receivers, doctors and other healthcare providers, who are three main types of users of cloud based chronic diseases healthcare platform. In these cases, the actions drew with cloud sharps are performed in the cloud based platform.

\section{User Case 1: From Doctors Perspective}

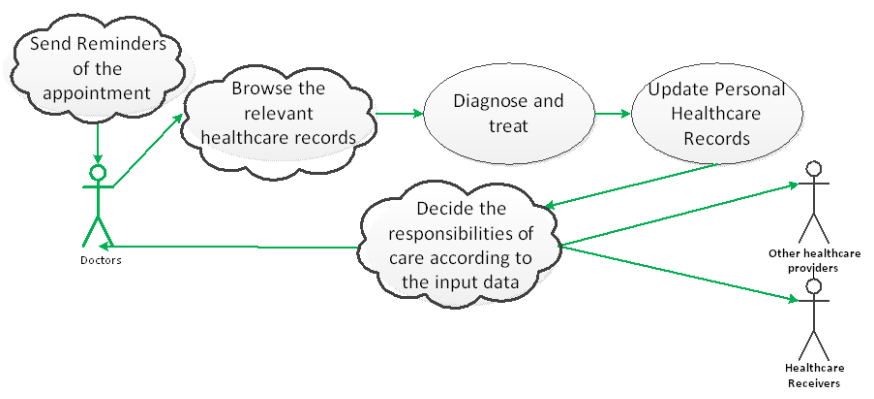

Figure 5 User Case 1: From Doctors Perspective

Doctors will receive reminders of the patients' appointment from the cloud before the patient visits. When meeting the patients, he or she will browse the relevant healthcare records stored in the cloud. Based on the records, the doctor will diagnose and treat the patient. After treatment, the doctor will update the personal healthcare records, as well as further care suggestions in the cloud. The cloud itself will decide the responsibilities of care and send the information to the responsible party.

User Case 2: From other Healthcare Providers Perspective

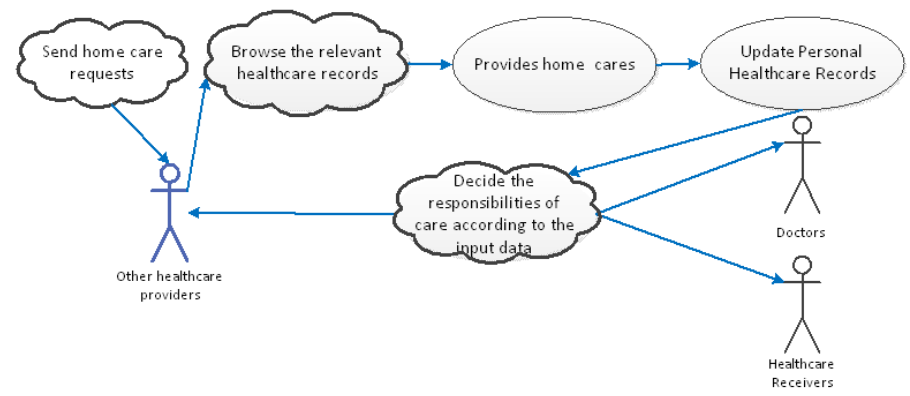

Figure 6 User Case 2: From other Healthcare Providers Perspective

An authorized healthcare provider can also browse the relevant healthcare records when he or she is required to provide healthcare to the receivers. Then the provider will provide home cares and update the related healthcare records. The same as other cases, the cloud itself will send the information of further care to the responsible party according to the input healthcare data.
User Case 3: From Healthcare Receivers Perspective

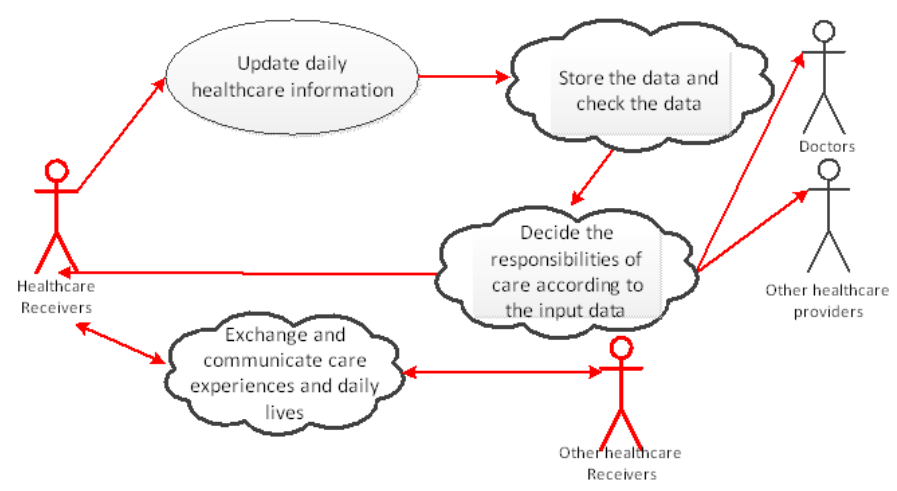

Figure 7 User Case 3: From Healthcare Receivers Perspective

Healthcare receivers with chronic diseases use some selfmonitoring devices to check their body parameters such as blood pressure and blood glucose. Then they update this data as daily healthcare information to the cloud. The cloud based platform stores the data and uses its embedded support decision systems to check the input data with the standard values. If the data is normal, it will send feedback to the receivers. Otherwise, the cloud will send the alarms to the responsible care providers based on different conditions automatically. Besides, healthcare receivers can also communicate with patients who have similar symptoms to share their care experiences and daily lives.

The action "Decide the responsibilities of care according to the input data" appears in all the three cases. It is a use of the strong data processing feature of cloud. The actions of browse and update personal healthcare information is a representation of data storage and exchange feature of cloud. Communicate with other patients is also benefit from the cloud's powerful data storage and exchange capability.

\section{DISCUSSION}

The proposed HCDH platform enables elderly an independent living at home and improves the quality of life even with chronic diseases. The services provided by cloud are ready to access at anytime and anywhere. It is designed to be available for $24 / 7$ services which is crucial in some emergency circumstance in need of patient records.

Since Cloud computing ensures that healthcare receivers can receive healthcare services anywhere, care receivers can choose the services based on their different types of chronic diseases, and the needs of individual can be met more accurately. After patients' electronic healthcare records and other related information are stored in the cloud, all authorized healthcare providers can browse the information for helping diagnose and treat care receivers cooperatively. Healthcare receivers as well as their relatives can immediately and easily browse their health record through the cloud to manage their own daily life. It also provides an online community for chronic diseases patients who have similar symptoms to share and learn each other. 
In addition, the process of this home based healthcare will generate large samples of patient self-recording health data. Consider the huge number of patients, there is a big volume of data to be processed. If patients volunteer to share their daily health data to other healthcare research institutions or providers, it will benefit the research of chronic diseases and give more appropriate treatment to the patients.

Although cloud computing based model provides many advantages, privacy, security and trust are still challenges when it is used in the healthcare domain. Because healthcare information is very sensitive, data privacy control mechanism must be applied before the information is massively published in the cloud. Choosing secure cloud providers is another essential factor of successful cloud HCDH.

\section{CONCLUSION}

In this paper, we presented some challenges and problems in effective chronic diseases healthcare based on some literature review. An online questionnaire was carried out to know patients' view of home based care and healthcare information sharing. We found that a new home-based eHealth approach is urgently required to meet the needs. By comparing main technical solutions, cloud computing could be the most proper enabling solution. A cloud platform of $\mathrm{HCDH}$ is proposed, and we also explained the actions of doctors, other healthcare providers and healthcare receivers by user cases. This platform puts healthcare receivers as the center, and integrates all the healthcare providers within the same platform. Through this shared platform, the interoperability among different healthcare providers as well as the self-management of healthcare receivers can be achieved.

\section{REFERENCES}

[1] United Nations, "Population Ageing and Development 2012 EU", Population Division Department of Economic and Social Affairs, United Nations, New York (2012)

[2] Jones, D. S., Podolsky, S. H., \& Greene, J. A. (2012). The burden of disease and the changing task of medicine. New England Journal of Medicine,366(25), 2333-2338.

[3] García-Lizana, F., \& Sarría-Santamera, A. (2007). New technologies for chronic disease management and control: a systematic review. Journal of telemedicine and telecare, 13(2), 62-68.

[4] Steg, H., Strese, H., Loroff, C., Hull, J., \& Schmidt, S. (2006). Europe is facing a demographic challenge Ambient Assisted Living offers solutions. IST project report on ambient assisted living.

[5] National eHealth - the strategy for accessible and secure information in health and social care (2011).

[6] Mell, P., \& Grance, T. (2011). The NIST definition of cloud computing (draft).NIST special publication, 800(145), 7 .

[7] Paré, G., Jaana, M., \& Sicotte, C. (2007). Systematic review of home telemonitoring for chronic diseases: the evidence base. Journal of the American Medical Informatics Association, 14(3), 269-277

[8]Braunstein, M. L. (2012). Health Informatics in the Cloud. Springer.

[9] Polisena, J., Tran, K., Cimon, K., Hutton, B., McGill, S., Palmer, K., \& Scott, R. E. (2010). Home telehealth for chronic obstructive pulmonary disease: a systematic review and meta-analysis. Journal of Telemedicine and Telecare, 16(3), 120-127.

[10] Holman, H., \& Lorig, K. (2004). Patient self-management: a key to effectiveness and efficiency in care of chronic disease. Public health reports, 119(3), 239

[11] Bodenheimer, T., Chen, E., \& Bennett, H. D. (2009). Confronting the growing burden of chronic disease: can the US health care workforce do the job?.Health Affairs, 28(1), 64-74.

[12] Beeler, G. W., Duteau, J. H., Grieve, G., McKenzie, L., \& Natarajan, R.

(2011). HL7 Version 3 Standard. Version 3 Ballot.
[13] Koes, B. W., van Tulder, M., Lin, C. W. C., Macedo, L. G., McAuley, J., \& Maher, C. (2010). An updated overview of clinical guidelines for the management of non-specific low back pain in primary care. European Spine Journal, 19(12), 2075-2094.

[14] Zhang, L., Wang, F., Wang, L., Wang, W., Liu, B., Liu, J., ... \& Wang, H. (2012). Prevalence of chronic kidney disease in China: a cross-sectional survey. The Lancet, 379(9818), 815-822

[15] Lin, C. C., Lee, R. G., \& Hsiao, C. C. (2008). A pervasive health monitoring service system based on ubiquitous network technology. international journal of medical informatics, 77(7), 461-469.

[16] Guo, Y., Hu, Y., Afzal, J., \& Bai, G. (2011, June). Using P2P technology to achieve eHealth interoperability. In Service Systems and Service Management (ICSSSM), 2011 8th International Conference on (pp. 1-5). IEEE.

[17] Hu, Y., Lu, F., Khan, I., \& Bai, G. (2012, December). A cloud computing solution for sharing healthcare information. In Internet Technology And Secured Transactions, 2012 International Conferece For (pp. 465-470). IEEE. [18] Dawoud, W., Takouna, I., \& Meinel, C. (2010, March). Infrastructure as a service security: Challenges and solutions. In Informatics and Systems (INFOS), 2010 The 7th International Conference on (pp. 1-8). IEEE.

[19] Mell, P., \& Grance, T. (2011). The NIST definition of cloud computing (draft).NIST special publication, $800,145$.

[20] Armbrust, M., Fox, A., Griffith, R., Joseph, A. D., Katz, R., Konwinski, A., ... \& Zaharia, M. (2010). A view of cloud computing. Communications of the ACM, 53(4), 50-58. 